a debate Patrimonio, turismo y género. Estrategias para integrar la perspectiva de género en el patrimonio histórico

| coordinan Margarita M. Birriel Salcedo, Carmen Rísquez Cuenca

\title{
La cultura como esencia de cambio
}

Ana Ruiz-Blanch | Instituto de Ciencias del Patrimonio (INCIPIT), Consejo Superior de Investigaciones Científicas (CSIC)

URL de la contribución <www.iaph.es/revistaph/index.php/revistaph/article/view/3736>

"En la 'transición del feudalismo al capitalismo' las mujeres sufrieron un proceso excepcional de degradación social que fue fundamental para la acumulación de capital y que esta ha permanecido así desde entonces"

(FEDERICI, 2004: 113).

Empiezo mi exposición aclarando que este escrito está en sintonía con el de Guadalupe Jiménez-Esquinas (De "añadir mujeres y agitar" a la despatriarcalización del patrimonio: la crítica patrimonial feminista), publicado en este número de revista ph (pp. 137-140). De hecho, ella compartió su texto con las compañeras en el Instituto de Ciencias del Patrimonio, donde desarrollamos nuestra actividad de investigación y formación constante. Lo estuvimos comentando y de estos comentarios salen estas palabras. Debe tenerse en cuenta a la hora de leerlo, pues no voy a repetir lo que ella ya ha dicho y que suscribo plenamente. Pero la complejidad de los dos términos que se discuten, patrimonio y género, requiere de numerosos puntos de vista, los necesarios para escanear todos los aspectos de esta relación ${ }^{1}$.

"El patrimonio es concebido como una realidad esencial preexistente, no como una construcción social" (PRATS, 2005). Esta concepción del patrimonio cultural aparece "con el desarrollo del capitalismo y la revolución industrial" (PRATS, 2005: 19) y representa las ideas que su marco de aparición contiene. Así, el patrimonio, se erige en una serie de monumentos (la propia idea de monumento), objetos y discursos que identifican a quienes los contemplan con un grupo, generalmente estado-nación y unos valores comunes relacionados con una determinada forma de ver la vida. Forma que a su vez se ve retroalimentada por esta identificación. Es lo que Laurajane Smith denomina discurso patrimonial autorizado (SMITH, 2006).
Silvia Federici (FEDERICI, 2004)² utiliza el término marxista acumulación primitiva para explicar cómo, con la aparición del salario (se refiere al que aparece con el capitalismo), una serie de actividades -realizadas por mujeres- (reproducción, mantenimiento doméstico, cuidados, etc.) se dejaron de considerar productivas, es decir merecedoras de un salario. Con ello, los propietarios de las fábricas y negocios consiguieron en realidad pagar el trabajo de dos personas a precio de una, el asalariado.

Del mismo modo, el discurso patrimonial autorizado es la acumulación primitiva simbólica de la idea de patrimonio, un rédito preestablecido que marca la dirección del discurso y lo hace crecer en esta dirección. Como tal, actúa con enorme ventaja frente a otros discursos patrimoniales y llega a constituir un régimen de verdad en el sentido que Foucault le da al término (FOUCAULT, 1992).

La reciente equiparación legal de los dos sexos ha desencadenado un profundo cambio simbólico en nuestras estructuras sociales, tan profundo que en realidad las cuestiona desde su raíz. Este cambio se va expresando lentamente en nuestros modos de hacer, como también se expresan las resistencias al mismo. El discurso patrimonial autorizado y la todavía poca valoración de los "trabajos femeninos" son expresión de estas resistencias. La combinación de ambas cosas da resultados que hay que tener en cuenta. Por ejemplo, si analizamos la creciente valoración del patrimonio cultural como forma de atraer turismo, debemos tener en cuenta que el negocio del turismo tiene uno de sus pilares de riqueza en trabajos que destacan por su precaria remuneración. Y que esto ocurre porque estos trabajos se asocian al mantenimiento doméstico. Un ejemplo claro son las condiciones laborales de las camareras de hotel, por citar uno de los más flagrante. 


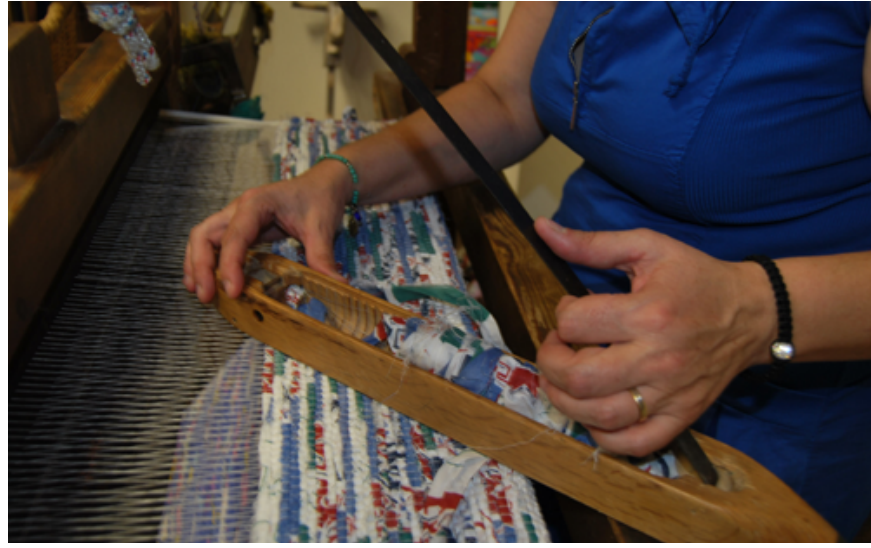

El negocio del turismo tiene uno de sus pilares de riqueza en trabajos que destacan por su precaria remuneración | foto Fondo Gráfico IAPH

El patrimonio cultural desde una perspectiva de género no puede pretender (o no sólo) visibilizar a aquellas mujeres que han sido importantes desde el punto de vista patriarcal, sino que, inevitablemente, buscará cambiar este punto de vista. Reconcebir, en definitiva, la propia idea de patrimonio. El empoderamiento de las mujeres deberá ser de todas, no de unas cuantas. Y este discurso, que clama horizontalidad, se hace automáticamente extensible a los hombres. De hecho, tiene poco sentido sin ellos.

Para buscar esta nueva concepción de patrimonio, deberemos encontrarnos en aquello común que nos referencia, en los afectos que se tejen en torno a lo que en común admiramos y nos ayuda a sentirnos seguras, acompañadas, identificadas, como personas y como grupo. "Si los seres humanos tuviéramos presente la complejidad de la realidad en la que hemos de sobrevivir, la angustia nos colapsaría, y nos impediría hacerlo" (HERNANDO, 2006: 223). Esta es la base, según Hernando, de la configuración de las identidades, los mecanismos grupales para defendernos de esta angustia, creando representaciones simbólicas colectivas que, lejos de dar una explicación a todo, nos ubican emocionalmente en una pertenencia grupal que nos permite "olvidar" lo que no podemos entender y por ende controlar. Limitamos nuestra visión de la realidad al sentido y representación del orden de la misma que el grupo al que pertenecemos narra (HERNANDO, 2002: 51-55). Así, las resistencias que presenta el profundo cambio simbólico que supone la igualdad legal de los sexos se ven reforzadas por la angustia que causa en cada persona la idea de quedarse sin referentes comunes. Sustituir unos referentes por otros no es tarea fácil y menos cuando esta sustitución supone un cambio radical en la forma de concebir la vida, tanto a nivel individual como colectivo. Además, se trata de un proceso complejo, global y mediatizado por nuevas tecnologías que cambian la propia concepción del espacio y del tiempo.

En este proceso aparece una cuestión muy interesante: el "qué" debemos cambiar se imbrica en el "cómo" debemos hacerlo. Sólo comprendiendo la profunda relación que hay entre el objetivo a conseguir y la manera de conseguirlo podremos avanzar hacia la consolidación del cambio simbólico que supone la perspectiva de género. Si nos paramos a analizar las iniciativas que integran en el patrimonio esta perspectiva, es más que probable que la gran mayoría respondan a propuestas innovadoras, y que sólo unas cuantas respondan a cauces tradicionales. Y es muy importante que sea así porque es en la manera como se hacen las cosas donde reside la cultura y es en la cultura donde reside la esencia de los cambios y de la propia humanidad. 
a debate Patrimonio, turismo y género. Estrategias para integrar la perspectiva de género en el patrimonio histórico | coordinan Margarita M. Birriel Salcedo, Carmen Rísquez Cuenca

\section{NOTAS}

1. Este trabajo se realiza en el marco de la concesión de financiación del Ministerio de Educación, Cultura y Deporte para la Formación de Profesorado Universitario (2015) y el proyecto de I+D del Plan Nacional, ParticiPat, Patrimonio y participación social: propuesta metodológica y revisión crítica (HAR2014-54869-R).

2. El libro Calibán y la bruja al que aquí hago referencia es también un excelente ejemplo de cómo se puede reescribir la historia, más allá de lo que Jiménez-Esquinas llama "añadir mujeres y agitar".

\section{BIBLIOGRAFÍA}

- FEDERICI, S. (2004) Calibán y la bruja: Mujeres, cuerpo y acumulación originaria. Madrid: Traficantes de Sueños, 2004

- FOCAULT, M. (1992) Microfísica del poder. Madrid: La Piqueta, 1992

- HeRnANDo Gonzalo, A. (2002) Arqueología de la Identidad. Madrid: Akal, 2002

- HERNANDO GoNZALO, A. (2006) Arqueología y Globalización: el problema de la definición del "otro" en la Postmodernidad. Complutum, 2006, n. ${ }^{\circ}$ 17, pp. 221-234

- PRATS, LL. (2005) Concepto y gestión del patrimonio local. Cuadernos de Antropología Social, 2005, n. ${ }^{\circ} 21$, pp.17-35

- SMITH, L. (2006) The uses of heritage. New York: Routledge, 2006 